\title{
Custom Mega Prosthesis in Metachronous Osteosarcoma
}

\author{
MV Natarajan', Mohamed Sameer M², Upasana Upadhyay ${ }^{3}$, MD Kumar ${ }^{4}$ \\ MN Orthopaedic Hospital, Chennai ${ }^{1-3}$ \\ Department of Orthopaedics, ESIC Medical College \& Postgraduate Institute of \\ Medical Sciences and Research, KK Nagar, Chennai ${ }^{4}$.
}

\begin{abstract}
Background: The objective of the current study was to determine the incidence, clinical and pathologic characteristics, and outcome of patients with conventional osteosarcoma who developed metachronous tumours and treated by limb salvage surgery with Custom Mega Prosthesis.

Methods: Among 1198 osteosarcoma patients who were treated with limb salvage surgery and implantation of custom mega prosthesis, 6 patients were found to have metachronous lesions. The absence of pulmonary metastases was confirmed by chest radiographs and computed tomography while radionuclide bone scan and biopsy were used to confirm the absence of skeletal metastases. The patients were treated by limb salvage surgery with custom mega prosthesis for the metachronous tumour and functional outcome was evaluated by MSTS scores.

Results: Index primary tumours involved the femur $(n=3)$ and the tibia $(n=3)$ and were treated with limb salvage surgery using endoprosthetic reconstruction. Single metachronous tumours developed in the all of these patients with the interval between identification of the primary tumour to development of the metachronous tumours varying from 18 months to 41 months. All metachronous tumours were treated with neoadjuvant chemotherapy and limb salvage surgery. We obtained excellent functional outcome for primary tumours and good functional outcome for metachronous tumours. Two patients succumbed to disease due to pulmonary and cerebral metastasis during follow-up.
\end{abstract}

Conclusions: With advances in survival rate in the multidrug chemotherapy era in the post tumoursresection period, advanced diagnostic modalities help in diagnosing metachronous osteosarcoma. It should be recognized as important sequelae in long-term survivors. Meticulous follow-up is required to permit early detection and successful therapeutic intervention. Limb salvage surgery has provided consistent good results in metachronous osteosarcoma patients.

Keywords: Metachronous tumours, osteosarcoma, skeletal metastases, limb salvage surgery.

\section{Introduction}

Eighty percent of patients with osteosarcoma are known consistently to harbour micro-metastases in the lungs at the time of diagnosis (1). These metastases are undetected in imaging studies. Untreated, they are detected
6-9 months later and usually are responsible for the patient's mortality. In a rather smaller group, skeletal metastases with soft tissue invasion were present with pulmonary metastasis.

In contrast, skeletal lesions may appear later, after treatment of the primary tumours in

Correspondence : Dr. Mayil Vahanan Natarajan, M.N. Orthopaedic Hospital, No:14, Bank Street, Kilpauk, Chennai -600010, India. Phone : 044-26442279.Email: drmayilnatarajan@me.com. 
the absence of pulmonary metastasis. These lesions are designated as metachronous tumours. They did not metastasize from the primary tumours or the lungs but developed later and spontaneously in other parts of the skeleton.

\section{Materials and Methods}

During the past 28 years, 1198 patients of osteosarcoma were treated by the senior author (MVN). All these patients had osteosarcoma at one site at the time of initial diagnosis. They were treated with neoadjuvant multidrug chemotherapy, tumour resection and implantation of custom mega prosthesis. Henceforth they were serially monitored for the presence of detectable pulmonary and skeletal metastases. Six of 1198 patients were identified with single post-therapy metachronous osteosarcomas. Before the discovery of the metachronous tumours, the lungs and skeleton had been continually free of disease.

\section{Results}

The primary lesions in these 6 patients were located in the following sites: distal femur $(n=3)$, proximal tibia $(n=2)$ and distal tibia $(n=1)$. These metachronous tumours appeared as single lesions in all these 6 patients. They were located in the proximal humerus $(n=2)$, proximal tibia $(\mathrm{n}=1)$, tibial diaphysis $(\mathrm{n}=1)$, proximal femur $(n=1)$ and distal radius $(n=1)$. The metachronous tumours occurred at long bones in $83 \%$ ( 5 out of 6 sites). Among the 6 patients who developed metachronous osteosarcoma, the mean age was 24.2 years and 5 out of 6 patients were males. The interval between the diagnoses of the primary tumours and the metachronous tumours varied from 18 to 41 months. Selected illustrations of primary and metachronous tumours in individual patients are depicted in Fig. 1 and 2.

The metachronous tumours, presented with characteristics similar to those of the primary tumours. Histologic characteristics of the primary tumours were as follows: osteoblastic $(n=3)$, chondroblastic $(n=2)$ and periosteal $(n=1)$. The diagnosis of all 6 metachronous tumours were confirmed by biopsy. The histology in 6 metachronous tumours were concordant with the corresponding primary tumours detected prior. The average survival period of these patients post-treatment of the metachronous tumours was 2.45 years, with 2 succumbing to disease at 8th and 18th month of follow-up. The mean

SITE 1
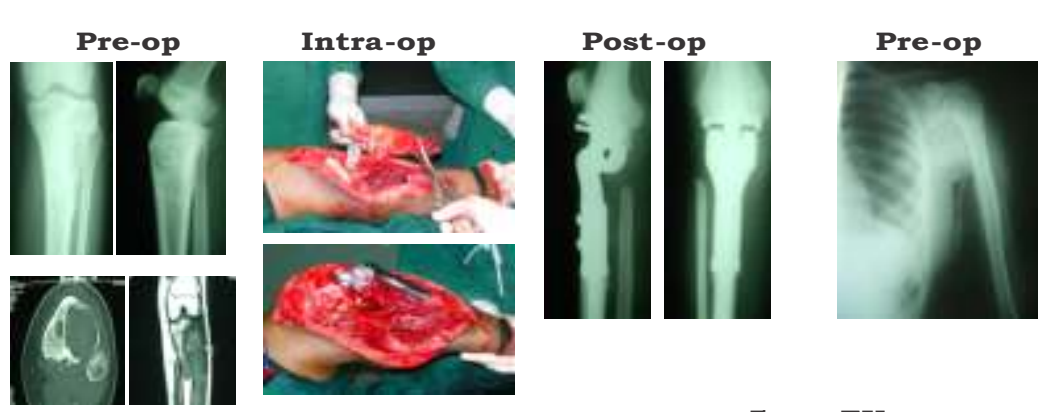

SITE 2 ( after 2 yrs FU)

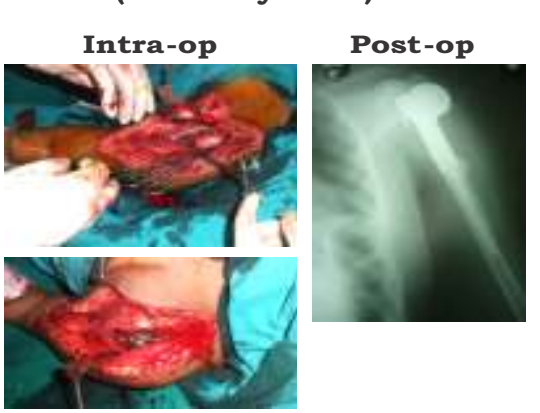

\section{5 yrs FU}
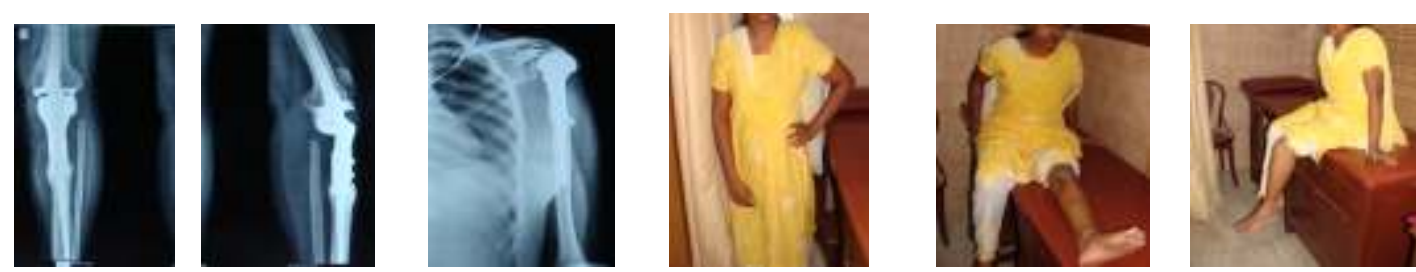

Fig. 1: Metachronous osteosarcoma ( PT - PH ) 
SITE 1

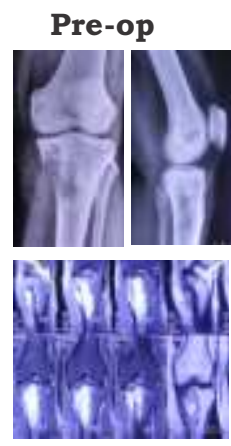

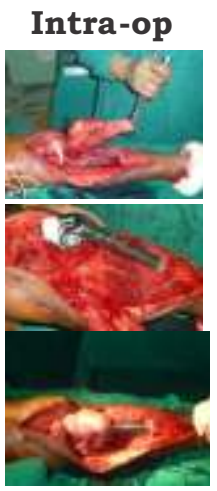

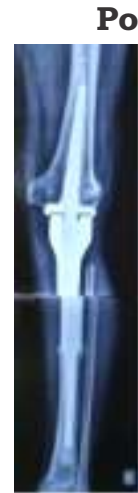

Post-op

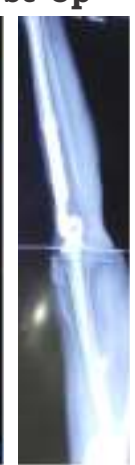

SITE 2 ( after 4 yrs FU)
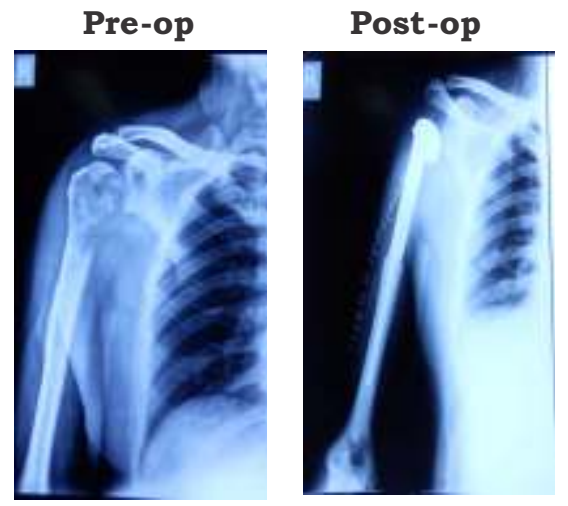
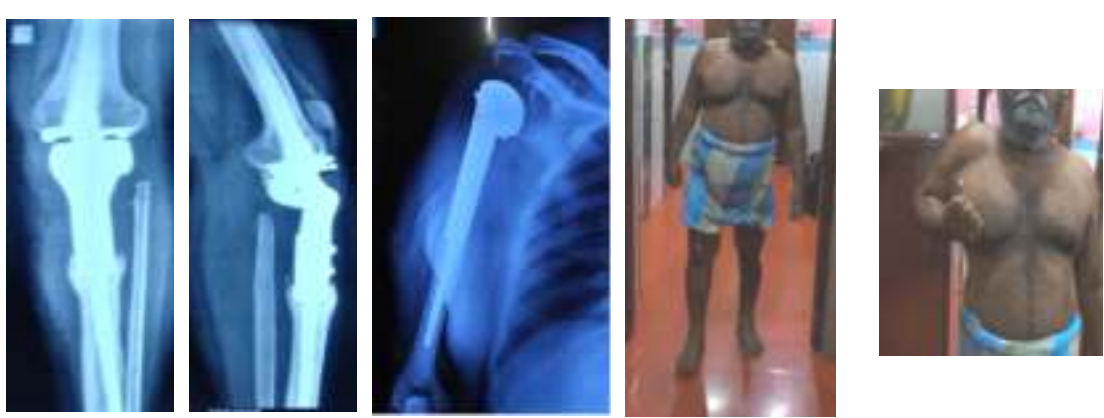

Fig. 2: Metachronous osteosarcoma ( PT - PH )

Musculoskeletal Tumour Society Score (MSTS) score for functional outcome of primary tumours was 22.9 while for metachronous tumours was 19.5 with poorer outcome noted at proximal humerus and distal tibia. The patients' details are depicted in Table 1.

\section{Discussion}

Lungs are the most common site for the development of metastases in patients with osteosarcoma. Skeletal metastases although less common, about 3.6-10\%, also were reported in early studies and are generally in association with pulmonary metastases (1). Lockshin and Higgins (2) similarly reported a $41 \%$ incidence of bone metastases among 22 osteosarcoma patients who were dying in hospital. These metastases were detected radiologically or at autopsy.
Compared with the detection of pulmonary and skeletal metastases (concurrently or later), the detection of single or multiple skeletal lesions without pulmonary involvement subsequent to the initial presentation of the primary tumour has been relatively uncommon. These lesions were termed as metachronous lesions (3). Several early reports suggested a multicentric origin and reported most lesions discovered in the absence of pulmonary metastases (4-13). This finding is in concurrence with our definition. These metachronous skeletal sites generally were similar to the sites affected by primary osteosarcoma. Corradi et al (14) reported 26 patients with 59 metachronous lesions with $76 \%$ of sites at long bones and $62 \%$ male predisposition. We report 6 cases of metachronous tumours in 1198 osteosarcoma patients (incidence: $0.5 \%$ ) with $83 \%$ sites at long bones and $83 \%$ male predisposition. 
Table1: Demographic details of limb salvage surgery for metachronous osteosarcoma (OS)

\begin{tabular}{|c|c|c|c|c|c|c|c|c|c|}
\hline $\begin{array}{l}\text { Sl. } \\
\text { No. }\end{array}$ & \begin{tabular}{|l} 
Name/P \\
atient \\
(Pt. \\
No.) \\
\end{tabular} & \begin{tabular}{|l} 
Age $/$ \\
Sex
\end{tabular} & Site 1 Diagnosis (A) & $\begin{array}{l}\text { Site } 1 \\
\text { Treatment }\end{array}$ & $\begin{array}{l}\text { Site } 2 \text { Diagnosis } \\
\text { (B) }\end{array}$ & $\begin{array}{l}\text { Interval } \\
\text { duration } \\
\text { (Yrs) }\end{array}$ & \begin{tabular}{|l} 
Site 2 \\
Treatment
\end{tabular} & $\begin{array}{l}\text { MSTS } \\
\text { Score }\end{array}$ & Outcome \\
\hline 1. & Pt1: ML & $\begin{array}{l}30 / \\
\mathrm{M}\end{array}$ & $\begin{array}{l}\text { Right Distal Femur } \\
\text { (DF) OS with } \\
\text { Metases -2004 }\end{array}$ & $\begin{array}{l}\text { CMP Right } \\
\text { DF }\end{array}$ & $\begin{array}{l}\text { Right Distal } \\
\text { Radius (DR) } \\
\text { OS- } 2007\end{array}$ & 3 & $\begin{array}{l}\text { CMP Right } \\
\text { DR }\end{array}$ & $\begin{array}{l}\text { A: } 24 \\
\text { B: } 21\end{array}$ & $\begin{array}{l}\text { 1.5yrs; Recurrence of } \\
\text { Metases/ Spine/Pelvis; died } \\
\text { of disease }\end{array}$ \\
\hline 2. & Pt2: $\mathrm{SH}$ & $18 / \mathrm{F}$ & $\begin{array}{l}\text { Left Proximal Tibia } \\
\text { (PT) OS- } 2005\end{array}$ & $\begin{array}{l}\text { CMP Right } \\
\text { PT }\end{array}$ & $\begin{array}{l}\text { Left Proximal } \\
\text { Humerus (PH) } \\
\text { OS -2007 }\end{array}$ & 1.75 & CMP Left PH & $\begin{array}{l}\text { A: } 22 \\
\text { B: } 20\end{array}$ & $\begin{array}{l}\text { 8yrs; Disease free interval; } \\
\text { continues to be disease free }\end{array}$ \\
\hline 3. & Pt3: SS & $\begin{array}{l}19 / \\
M\end{array}$ & $\begin{array}{l}\text { Left Distal Femur } \\
\text { (DF) OS- } 2006\end{array}$ & CMP Left DF & $\begin{array}{l}\text { Right Proximal } \\
\text { Femur (PF) OS- } \\
2008\end{array}$ & 1.9 & $\begin{array}{l}\text { CMP Right } \\
\text { PF }\end{array}$ & $\begin{array}{l}\text { A: } 24 \\
\text { B: } 21\end{array}$ & $\begin{array}{l}0.6 \mathrm{yrs} \text {; Disease free } \\
\text { interval-REC-died of } \\
\text { pulmonary and cerebral } \\
\text { Metases }\end{array}$ \\
\hline 4. & Pt4: VA & $\begin{array}{l}11 / \\
\mathrm{M}\end{array}$ & $\begin{array}{l}\text { Right Distal Femur } \\
\text { (DF) OS- } 2011\end{array}$ & $\begin{array}{l}\text { CMP Right } \\
\text { DF }\end{array}$ & $\begin{array}{l}\text { Right Tibia } \\
\text { Diaphysis OS- } \\
2012\end{array}$ & 1.75 & $\begin{array}{l}\text { CMP Right } \\
\text { Tibia }\end{array}$ & $\begin{array}{l}\text { A: } 23 \\
\text { B: } 18\end{array}$ & 3.5yrs; Disease free; alive \\
\hline 5. & Pt5:MP & $\begin{array}{l}17 / \\
M\end{array}$ & $\begin{array}{l}\text { Left Distal Tibia } \\
\text { (DT) OS -2013 }\end{array}$ & CMP Left DT & $\begin{array}{l}\text { Left Proximal } \\
\text { Tibia (PT) OS- } \\
2015\end{array}$ & 2.1 & Total Tibia & $\begin{array}{l}\text { A: } 23 \\
\text { B: } 18\end{array}$ & $\begin{array}{l}0.5 \mathrm{yrs} \text {; Disease free } \\
\text { interval; alive; infection }\end{array}$ \\
\hline 6. & Pt 6: N & $\begin{array}{l}50 / \\
\mathrm{M}\end{array}$ & $\begin{array}{l}\text { Left Proximal Tibia } \\
\text { (PT) OS - } 2011\end{array}$ & CMP Left PT & $\begin{array}{l}\text { Right Proximal } \\
\text { Humerus (PH) } \\
\text { OS-2015 }\end{array}$ & 3.75 & $\begin{array}{l}\text { CMP Right } \\
\text { PH }\end{array}$ & $\begin{array}{l}\text { A: } 21 \\
\text { B: } 19\end{array}$ & $\begin{array}{l}0.5 \mathrm{yrs} \text {; Disease free } \\
\text { interval; continues to be } \\
\text { disease free }\end{array}$ \\
\hline
\end{tabular}

The etiology and pathogenesis of metachronous osteosarcoma are unknown. Batson et al (15) postulated that the metastases migrated through the vertebral venous system and by passed the portal, caval, and pulmonary circulations. It is now known that metachronous osteosarcoma may occur as a single lesion (16, $17)$ or as multiple lesions $(7,16,17)$. Fitzgerald et al (10) described 12 patients with multiple metachronous osteosarcoma with 4 patients developing a third metachronous tumour and 2 patients developing a fourth metachronous tumour. It was not possible to determine whether the metachronous sarcomas represented late metastases or new 'primary' tumours. We report 6 cases of single metachronous osteosarcoma in our study. There are two classifications for metachronous osteosarcoma $(12,18)$.

The clinical and radiographic features generally resemble those of primary 'classic' osteosarcoma $(1,2)$. Howat et al reported a case of the multifocal metachronous periosteal variety (7). Because the blood supply to the periosteum is poor compared with the blood supply to intramedullary bone, they considered their cases of periosteal osteosarcoma of primary origin. We found all our metachronous lesions having same clinical, radiological and histopathological resemblance to the index primary tumour.

Speculation has been raised that other preexisting conditions, such as Rothmund-Thomson syndrome, Paget disease, Fanconi anaemia, thyroid adenoma, childhood retinoblastoma, carcinoma of bladder and other genitourinary tumours, may contribute to the development of metachronous osteosarcoma. These diseases and cancerous conditions are known to be associated with the development of osteosarcoma and other malignant tumours, and its occurrence with osteosarcoma has been noted (17-21). We report all 6 cases, resembling the previously detected primary tumour. None of 6 patients in our series had bilateral retinoblastoma as all patients were screened and were evaluated thoroughly using PET scan.

In one of the large reported studies of metachronous osteosarcoma by Fitzgerald et al (10), the interval between discovery of the primary and metachronous lesions varied from 9 months to 14 years. Aung et al (13) reported the median latency interval between the diagnosis of the primary and the metachronous tumours was 1.5 years. Corradi et al (14) reported the interval 
between diagnosis of primary osteosarcomas and metachronous tumour, ranging from 7 to 171 months (median: 21 months). In our series, the interval between discovery of the primary tumours and the metachronous tumors varied from 20 to 41 months (mean: 27 months, i.e. 2.4 years).

In the study by Fitzgerald et al (10), the survival post-metachronous tumour excision and endoprosthetic replacement varied from 5 months to 11 years. Aung et al (13) reported that survival was found to be correlated with time to development of the metachronous tumour and longer time interval from diagnosis of the primary to the metachronous osteosarcoma correlates with the prognosis. In study by Jaffe et al (22), the 5-year post-metachronous survival rate in patients who developed metachronous tumours 24 months from and after diagnosis of the primary osteosarcoma were $8 \%$ and $61 \%$, respectively. In our study, the survival varied from 8 months to 8 years with two patients succumbing to metastasis at 8 th and 18 th month. However, we could not conclude that time interval from diagnosis correlated with prognosis or survival.

\section{Conclusion}

With improvement in the cure rate, metachronous osteosarcoma should be recognized as important sequelae in long-term survivor. Serial surveillance is required to permit early detection and successful therapeutic intervention. Upon the discovery of metachronous osteosarcoma, it should be treated always with curative intent. Limb salvage surgery using custom endoprosthetic replacement provides predictable results in the management of metachronous tumours with good to excellent functional outcome.

\section{References}

1. Jaffe $\mathrm{N}$ (1985). Chemotherapy in osteosarcoma: advances and controversies. In : Experimental and clinical progress in cancer chemotherapy. Maggia FM, ed. Boston: M Nyhoff Publishers, 223-233.

2. Lockshin MD, Higgins ITT (1966). Bone metastases in osteogenic sarcoma. Arch Intern Med 118:203-204.

3. Jaffe N, Pearson P, Yasko AW, Lin P, Herzog C, Raymond K (2003). Single and multiple metachronous osteosarcoma tumors after therapy. Cancer 98(11) : 2457-2466.

4. Simodynes EE, Jardon OM, Connolly JF (1981). Multiple metachronous osteosarcoma with eleven-year survival. A case report. J Bone Joint Surg Am 63:317-322.

5. Price CH, Truscott DE (1957). Multifocal osteogenic sarcoma; report of a case. $J$ Bone Joint Surg Br 39-B(3):524-533.

6. Mahoney JP, Spanier SS, Morris JL (1979). Multifocal osteosarcoma : a case report with review of the literature. Cancer 44:1897-1907.

7. Howat AJ, Dickers DR, Boldt DW, et al (1986). Bilateral metachronous periosteal osteosarcoma. Cancer 58:1139-1143.

8. Moseley JE, Bass MH (1956). Sclerosing osteogenic sarcomatosis. A radiologic entity. Radiology 66:41-45.

9. Mauk RH, Carpenter EB (1959). Multiosseous occurrence of sclerosing type osteogenic sarcoma. South Med J 52:858-860.

10. Fitzgerald RH, Dahlin DC, Sim FH (1973). Multiple metachronous osteogenic sarcoma. Report of twelve cases with two long-term survivors. $J$ Bone Joint Surg Am 55:595-605. 
11. Parham DM, Pratt CB, Parvey LS, Webber BL, Champion J (1985). Childhood $\mathrm{mult}$ ifocal osteosarcoma. Clinicopathologic and radiologic correlates. Cancer 55:2653-2658.

12. Amstutz HC (1969). Multiple osteogenic sarcomata--metastatic or multicentric? Report of two cases and review of literature. Cancer 24:923-931.

13. Aung L, Gorlick R, Healey JH, et al (2003). Metachronous skeletal osteosarcoma in patients treated with adjuvant and neoadjuvant chemotherapy for nonmetastatic osteosarcoma. J Clin Oncol 21:342-348.

14. Corradi D, Wenger DE, Bertoni F, et al (2011). Multicentric osteosarcoma : clinicopathologic and radiographic study of 56 cases. Am J Clin Pathol 136:799807.

15. Batson OV (1967). The vertebral system of veins as a means for cancer dissemination. Prog Clin Cancer 3:1-18.

16. Lee HJ, Kim IO, Kim WS, et al (2002). Metachronous multifocal osteosarcoma: a case report and literature review. Clin Imaging 26:63-68.

17. Kim MJ, Suh JS, Park CY (1990). Metachronous osteosarcoma; A case report. J Korean Radiol Soc 26:940-943.
18. Lowbeer L (1968). Multifocal osteosarcomatosis: a rare entity. Bull Pathol 9:52-53.

19. Spurney C, Gorlick R, Meyers PA, Healey JH, Huvos AG (1998). Multicentric osteosarcoma, Rothmund-Thomson syndrome, and secondary nasopharyngeal non-Hodgkins lymphoma: a case report and review of the literature. $J$ Pediatr Hematol Oncol 20:494-497.

20. Potepan P, Luksch R, Sozzi G, et al (1999). Multifocal osteosarcoma as second tumor after childhood retinoblastoma. Skeletal Radiol 28:415-421.

21. Chan H, Pratt CB (1977). A new familial cancer syndrome: a specimen of malignant and benign tumours including retinoblastoma, carcinoma of the bladder and other genitourinary tumors, thyroid adenoma and a probable case of multifocal osteosarcoma. J Natl Cancer Inst 58:205-207.

22. Jaffe N, Pearson P, Yasko AW, et al (2003). Single and multiple metachronous osteosarcoma tumors after therapy. Cancer 98:2457-2466. 